\title{
Prevalence of humeral head osteochondrosis in the Greater Swiss Mountain dog and the Border Collie in Switzerland.
}

Ohlerth, Stefanie ; Senn, S ; Geissbühler, U ; Kircher, Patrick R ; Flückiger, Markus

\begin{abstract}
Osteochondrosis (OC) is common in large-breed dogs. According to the breeding guidelines of the Swiss kennel clubs, the shoulder joints are included in the radiographic screening for joint diseases in the Greater Swiss Mountain dog (GSMD) and the Border Collie (BC) since 1993 and 2003, respectively. The aim of this study was to estimate the overall prevalence of humeral head OC in these 2 breeds in Switzerland based on the data of the Swiss National Dysplasia Committees. All radiographs were re-evaluated to assess single radiographic changes. From 1993 and 2003, accordingly, until 2013, the overall prevalence was 14\% for the GSMD and 8\% for the BC, respectively. Affected joints showed a focally reduced opacity or a flattened/indented contour of the caudal section of the humeral head. Articular flaps were only seen occasionally. Degenerative joint disease was significantly more common in OC affected joints (GSMD: 32\%; BC: 20\%) than in joints without OC. The present study is the first report on the prevalence of humeral head OC in a large cohort of GSMD and the BC over a long study period. In comparison to other breeds, the herein reported prevalences are in the mid to upper range. Results of the present study should alert veterinarians to the disease in these breeds and may serve as a starting point for further epidemiological and genetic studies.
\end{abstract}

DOI: https://doi.org/10.17236/sat00091

Other titles: Prävalenz der Osteochondrose im Schultergelenk beim Grossen Schweizer Sennenhund und Border Collie in der Schweiz

Posted at the Zurich Open Repository and Archive, University of Zurich ZORA URL: https://doi.org/10.5167/uzh-128992

Journal Article

Published Version

Originally published at:

Ohlerth, Stefanie; Senn, S; Geissbühler, U; Kircher, Patrick R; Flückiger, Markus (2016). Prevalence of humeral head osteochondrosis in the Greater Swiss Mountain dog and the Border Collie in Switzerland. Schweizer Archiv für Tierheilkunde, 158(11):749-754.

DOI: https://doi.org/10.17236/sat00091 


\title{
Prevalence of humeral head osteo- chondrosis in the Greater Swiss Mountain dog and the Border Collie in Switzerland
}

\author{
S. Ohlerth ${ }^{1}$, S. Senn' ${ }^{1}$ U. Geissbühler ${ }^{2}$, P. Kircher ${ }^{1}$, M. Flückiger ${ }^{1}$ \\ ${ }^{1}$ Klinik für Bildgebende Diagnostik, Departement für Kleintiere, Vetsuisse-Fakultät, Universität Zürich; \\ ${ }^{2}$ Klinische Radiologie, Departement für klinische Veterinärmedizin, Vetsuisse-Fakultät, Universität Bern
}

\begin{abstract}
Summary
Osteochondrosis (OC) is common in large-breed dogs. According to the breeding guidelines of the Swiss kennel clubs, the shoulder joints are included in the radiographic screening for joint diseases in the Greater Swiss Mountain dog (GSMD) and the Border Collie (BC) since 1993 and 2003, respectively. The aim of this study was to estimate the overall prevalence of humeral head OC in these 2 breeds in Switzerland based on the data of the Swiss National Dysplasia Committees. All radiographs were re-evaluated to assess single radiographic changes. From 1993 and 2003, accordingly, until 2013, the overall prevalence was $14 \%$ for the GSMD and $8 \%$ for the $\mathrm{BC}$, respectively. Affected joints showed a focally reduced opacity or a flattened/indented contour of the caudal section of the humeral head. Articular flaps were only seen occasionally. Degenerative joint disease was significantly more common in OC affected joints (GSMD: 32\%; BC: 20\%) than in joints without OC. The present study is the first report on the prevalence of humeral head OC in a large cohort of GSMD and the $\mathrm{BC}$ over a long study period. In comparison to other breeds, the herein reported prevalences are in the mid to upper range. Results of the present study should alert veterinarians to the disease in these breeds and may serve as a starting point for further epidemiological and genetic studies.
\end{abstract}

Keywords: osteochondrosis, OC, Greater Swiss Mountain dog, Border Collie, prevalence

\section{Prävalenz der Osteochondrose im Schultergelenk beim Grossen Schweizer Sennenhund und Border Collie in der Schweiz}

Osteochondrose (OC) ist eine häufige Erkrankung bei grossen Hunderassen. Für eine Zuchtzulassung in der Schweiz müssen beim Grossen Schweizer Sennenhund (GSSH) seit 1993 und beim Border Collie (BC) seit 2003 die Schultergelenke obligatorisch auf OC geröntgt werden. Das Ziel dieser Studie war es, die Prävalenz von OC im Schultergelenk bei diesen beiden Rassen in der Schweiz zu bestimmen. Die Grundlage bildeten die Daten der schweizerischen Dysplasie-Kommissionen. Alle Röntgenbilder wurden von den Autoren nochmals ausgewertet, um die diversen Röntgenveränderungen zu erfassen. Die Gesamt-Prävalenz von Schulter-OC betrug für den GSSH 14\% von 1993 bis 2013, und 8\% für den BC während der Jahre 2003 bis 2013. Als positive OC-Fälle wurden eine fokal verminderte Röntgendichte oder eine abgeflachte bzw. eine eingedellte Form des $\mathrm{Hu}$ merskopfes gewertet. Ein mineralisierter Flap wurde nur gelegentlich gesehen. Arthrose wurde signifikant häufiger bei OC-betroffenen Gelenken gefunden (GSSH: 32\%; BC: $20 \%$ ). Die vorliegende Studie berichtet als erste Publikation über die Prävalenz der Schultergelenk-OC in den beiden untersuchten Rassen über einen längeren Zeitraum und bei einer grossen Anzahl Tiere. Die bestimmten Prävalenzen liegen im Vergleich zu anderen Rassen im mittleren bis oberen Bereich. Die Ergebnisse der vorliegenden Studie sollen die Tierärzteschaft auf dieses Krankheitsbild bei den beiden Rassen aufmerksam machen und können als Ausganspunkt für weiterführende epidemiologische und genetische Studien dienen.

Schlüsselwörter: Osteochondrose, OC, Grosser Schweizer Sennenhund, Border Collie, Prävalenz
DOI $10.17236 /$ sat00091

Received: 08.01.2016 Accepted: 08.03.2016 
Prevalence of humeral head osteochondrosis in the Greater Swiss Mountain dog and the Border Collie in Switzerland

S. Ohlerth et al.

\section{Introduction}

Osteochondrosis (OC) represents a growth dysfunction of the epiphyseal growth cartilage, i.e. a focal disturbance of enchondral ossification. This leads to failure of calcification and/or failure of vascular invasion of the epiphyseal growth cartilage finally impeding its conversion to bone (Ekman and Carlson, 1998). In contrast to the avascular articular cartilage, the epiphyseal growth cartilage is vascularized with vessels originating from the surrounding perichondral plexus. In the early stage of articular osteochondrosis (osteochondrosis latens), a lesion is grossly not visible and is characterized histologically by a focal area of necrosis confined to the growth cartilage neither involving the articular cartilage nor the underlying subchondral bone. As soon as a lesion extends into the subchondral bone or articular cartilage, it becomes visible macroscopically and radiographically and is defined as osteochondrosis manifesta. This area is susceptible to mechanical stress and the overlying articular cartilage can develop fissures. Eventually, a loose intraarticular cartilage fragment may form (osteochondrosis dissecans [OCD]). Such a joint mouse can grow by absorbing nutrients from the synovial fluid and persist as cartilage body. Ossification can only happen if it is covered by a synovial fold and thus becomes supplied with blood vessels. Invasion of cartilage with blood vessels is required for enchondral ossification (Ytrehus et al., 2007). OC can cause joint incongruity resulting in degenerative joint disease (Johnston, 1998).

Regarding the pathogenesis, formation of a fragile cartilage, failure of chondrocyte differentiation, subchondral bone necrosis, and failure of blood supply to the growth cartilage have been proposed; in the recent literature, the last cause is regarded the most likely initial step (Ytrehus et al., 2007).

The etiology of OC is complex and considered multifactorial. The most commonly cited etiologic factors are heredity, gender, high rate of long bone growth, anatomic conformation, trauma, and dietary imbalances. Due to a prolonged and intense growth phase, OC occurs more often in male than female dogs (Demko and McLaughlin, 2005). Oversupply of calcium and phosphorus as well as excess energy intake have been shown to increase the risk of developing OC (Richardson and Zentek, 1998). Moderate heritability estimates have been reported for the Bernese Mountain dog with a value of 0.4 (Hartmann et al., 2010). So far, no genetic studies exist for the Border Collie (BC) or the Greater Swiss Mountain dog (GSMD).

OC of the humeral head is a common disease among young large-breed dogs and certain breeds are at increased risk e.g. the Bernese Mountain dog, Labrador and Golden Retriever, BC, and Great Dane (LaFond et al., 2002; Maddox et al., 2013). Small breeds are less likely affected (Bruggeman et al., 2010). So far, prevalences of $\mathrm{OC}$ in the canine shoulder joint have been reported only for breeds in Belgium and the US (Coopman et al., 2008; Morgan et al., 1999). Occurrence of OC is more common in the shoulder joint than in other joints and often occurs bilateral. Defects are typically found in the caudocentral or caudomedial aspect of the humeral head (Johnston, 1998). Radiographic examinations are most commonly used to diagnose OC of the scapulohumeral joint. The mediolateral extended projection is suited best for the visualisation of alterations of the subchondral bone such as flattening, indentation, subchondral bone lysis, and other findings such as free calcified cartilage fragments in the caudal pouch or the bicipital tendon sheath, and arthrosis. The caudocranial view may be of value for the localization of intraarticular fragments; however, it is rarely used for initial diagnosis (Kippenes and Johnston, 1998).

In Switzerland, radiographic screening for humeral head OC has become mandatory for breeding GSMD and BC since 1993 and 2006, respectively. Mediolateral views taken in neutral position of both shoulder joints are submitted to the Swiss National Dysplasia Committees in Berne and Zurich for official scoring. The objectives of the present study were first to estimate the overall prevalence of humeral head OC in the GSMD and $\mathrm{BC}$ in Switzerland based on the data of the Swiss National Dysplasia Committees. Second, all radiographic films were re-evaluated by the authors to study the prevalence of various radiographic changes associated with humeral head OC.

\section{Animals, Material and Methods}

\section{Animals}

Dogs were included in the study if either official scoring documents or radiographs for official scoring were available in the archives and electronic databases of the Swiss National Dysplasia Committees. Both, analogue and digital films were included.

\section{Greater Swiss Mountain dog}

From 1993 to the end of 2013, the Swiss National Dysplasia Committees scored a total of 354 pedigree GSMDs for humeral head OC. For three dogs, official scoring documents and radiographs were missing; consequently, only 351 data sets were available for statistical analysis. For another 15 GSMDs, radiographs had been sent back to the owners and were not available for re-evaluation. The median age was 605 days (range, 141-2134 days); 168 male (48\%) and 183 female (52\%) dogs were assessed. 


\section{Border Collie}

From 2003 to the end of 2013, 516 pedigree BCs were scored officially for humeral head OC. Official scoring documents and radiographs were missing for 5 dogs; therefore, official scores were available for 511 BCs. Radiographs of another 16 BCs had been sent back to the owners and were not available for re-evaluation. The median age was 537 days (range, 342-3897 days); 253 male $(49.5 \%)$ and 258 female $(50.5 \%)$ dogs were assessed.

\section{Radiographic re-evaluation}

Mediolateral radiographs of the shoulder joints of 336 GSMD and 495 BC were available for re-evaluation. Three observers (SS, MF, SO) scored a fraction of the films independently; panellists were not blinded for the official scores. If results of re-evaluation were not identical with the official scores, films were discussed with all observers for a final decision. The following criteria at the caudal part of the humeral head were assessed: shape (round, flattened, focally indented), presence of a mineralized flap (yes/no), and appearance of the subchondral bone (normal, focal radiolucency, sclerosis). Presence and location of osteophytes were also noted. A shoulder joint free of OC (score $=0$ ) was defined as a round humeral head without evidence of remodelling in the subchondral bone or presence of a mineralised flap (Fig. 1). A joint was considered affected by OC (score $=1$ ) if at least one of the following findings was present: flattened or indented contour, focal subchondral radiolucency or sclerosis of the caudal portion of the humeral head, mineralised flap. The presence of osteophytes alone did not result in a score 1 since causes other than OC could not be ruled out (ligament problems, trauma). Each joint was scored independently. Total score was 1 , if one or both joints were affected by OC.

Descriptive statistics and the Pearson chi-square test for the analysis of the association between gender or degenerative joint disease and total score were calculated using the SPSS statistics program (Version 19, IBM Corporation, Armonk, New York).

\section{Results}

\section{Greater Swiss Mountain dog}

Between 1993 and 2013, the overall prevalence of OC was 14\% (49 dogs, 38 right and 31 left joints); 41\% (20 dogs) were affected bilaterally. In total, $14 \%$ of the male and $12 \%$ of the female GSMD were affected; the difference was statistically not significant $(p=0.53)$. While the number of scored dogs increased markedly over the last 20 years (Fig. 1A), the 3-year-prevalence decreased from more than $30 \%$ to $12 \%$ (Fig. 1B). However, in the beginning, only a low number of dogs were evaluated. Of the 69 affected joints, the caudal portion of the humeral head was flattened or indented in 20 and 33 dogs, respectively. A focal radiolucent area in the subchondral bone without alteration of the contour of the humeral head was noted in the other 16 joints. Additionally, a mineralised flap was identified in 11 joints $(16 \%)$. Subchondral sclerosis alone without any other radiographic abnormalities was not seen. Osteophyte formation on the caudal margin of the humeral head and/or the caudal or cranial margin of the glenoid cavity was noted in 22 joints (32\%) and was significantly more common than in OC-free joints $(2.6 \%)$ $(p<0.001)$.

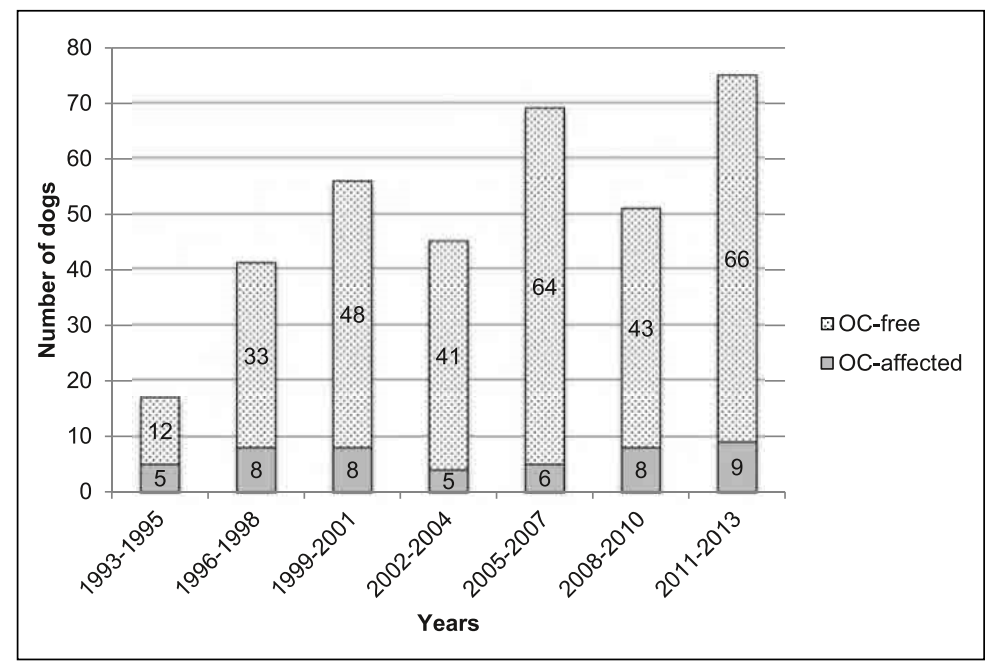

Figure 1A: Absolute numbers of OC-free and OC-affected Greater Swiss Mountain dogs. The total number of officially scored dogs has increased mildly over the years.

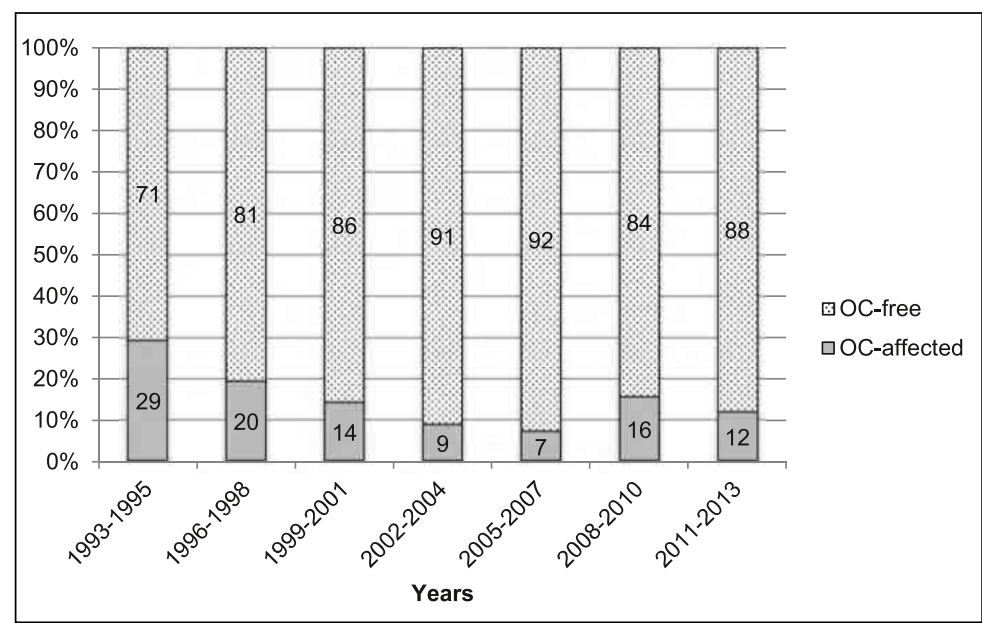

Figure 1B: In relation to the proportion of OC-free Greater Swiss Mountain dogs, the percentage of affected dogs decreased during 2 decades.
Prevalence of humeral head osteochondrosis in the Greater Swiss Mountain dog and the Border Collie in Switzerland

S. Ohlerth et al. 
Prevalence of humeral head osteochondrosis in the Greater Swiss Mountain dog and the Border Collie in Switzerland

S. Ohlerth et al.

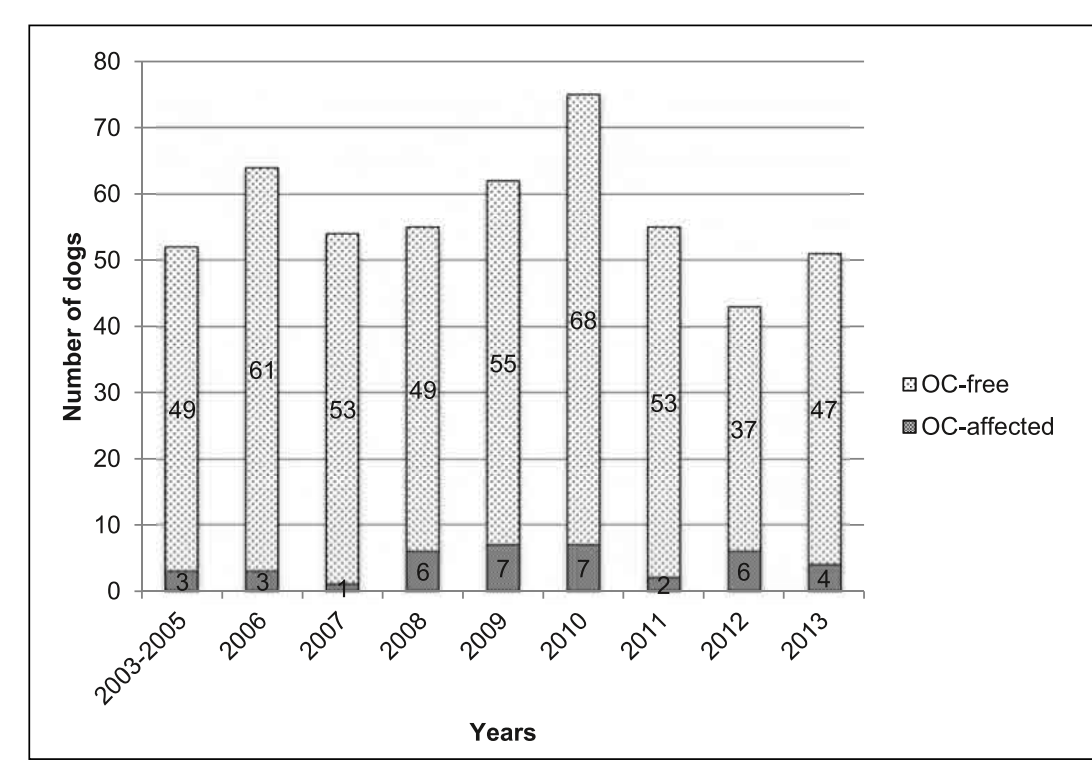

Figure 2A: Absolute numbers of OC-free and OC-affected Border Collies dogs.

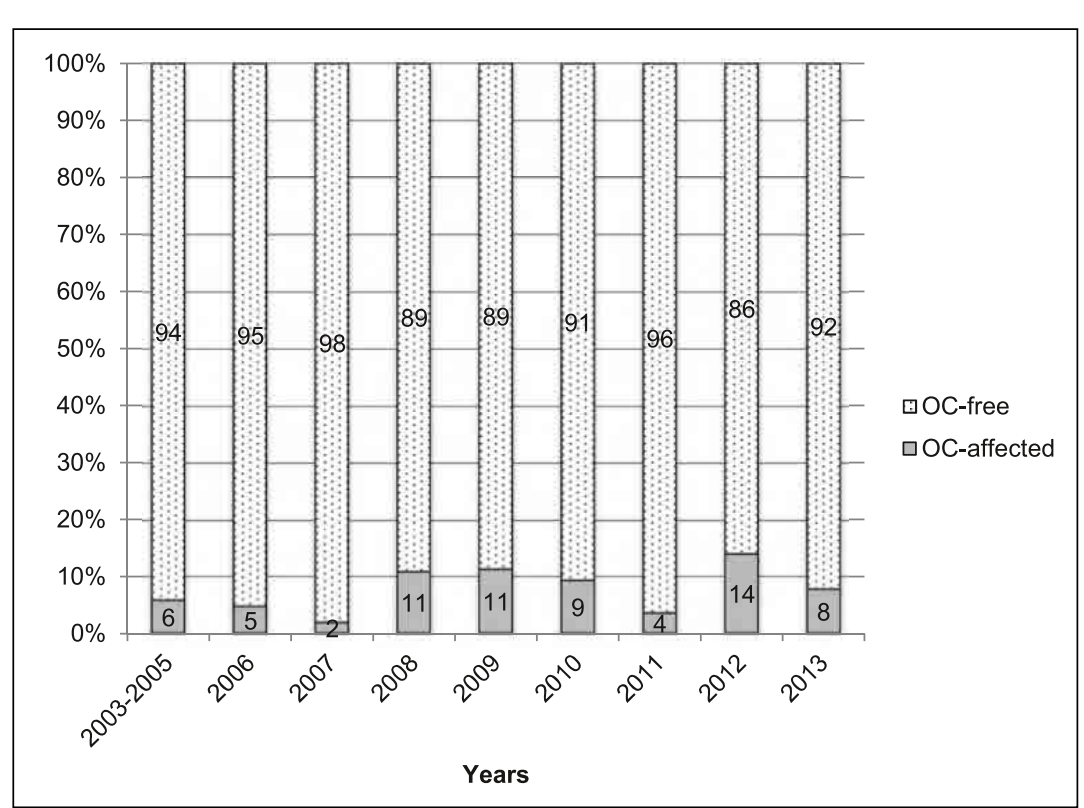

Figure 2B: During the study period of 10 years, the percentage of affected Border Collies did not markedly change.

\section{Border Collie}

Between 2003 and 2013, the overall prevalence of OC was $8 \%(39 \mathrm{dogs}) ; 15 \%(6 \mathrm{dogs})$ were affected bilaterally (23 right and 22 left joints). Overall, $6 \%$ of the male and $8 \%$ of the female BC were affected; the difference was statistically not significant $(p=0.52)$. Neither the number of scored dogs nor the prevalence of OC showed a clear trend over the investigated period of 10 years (Fig. 2). Of the 45 affected joints, the caudal portion of the humeral head was flattened or indented in 15 and 24 dogs, respectively. A focal radiolucent area in the subchondral bone without alteration of the contour of the humeral head was noted in 6 joints. A mineralised flap was identified in 3 joints (7\%). Subchondral sclerosis alone without any other radiographic changes was not seen. Osteophyte formation was noted in 9 OC-affected joints $(20 \%)$ and it was significantly more common than in OC-free joints $(2.8 \%)(p<0.001)$.

\section{Discussion}

Scientific literature on the prevalence of humeral head $\mathrm{OC}$ in the dog is scarce. A prevalence of $3.7 \%$ was reported in a large cohort of Labrador retrievers in the U.S. in the late 1990s (Morgan et al., 1999). For the Bernese mountain dog, a prevalence of $1.9 \%$ was published in a large study in Germany (Hartmann, 2010). In Belgium, reported prevalences for the GSMD and the BC were $10 \%$ and $7 \%$, respectively (Coopman et al., 2008; Coopman et al., 2014). However, only 30 GSMD and $14 \mathrm{BC}$ were included during a study time period of 4.5 years. In comparison, the herein reported data comprise a period of 21 (GSMD) and 11 (BC) years and overall prevalences are in the mid to upper range with 14\% (GSMD) and 8\% (BC). Prevalence of humeral head OC in the GSMD dropped mildly over the years. However, the presented data only reflects the situation in a subgroup of both breeds in Switzerland, e.g. breeding dogs. The true prevalence of humeral head OC in all Swiss dogs of both breeds remains unknown. According to the Swiss breeding clubs of the GSMD and the BC, during the study period there has been a 4 to 6 -fold number of raised puppies compared to the number of presently investigated dogs. Consequently, we assume a high number of unreported OC-affected cases. As previously reported, $\mathrm{OC}$ was often diagnosed bilaterally in the present study. Bilateral affection was more common in the GSMD than in the BC. Although male dogs are at a higher risk to develop OC in general, no statistically significant association between gender and official score was found in the Swiss populations.

Radiographs included in the present study were re-evaluated to assess single radiographic criteria. Most commonly, a focally reduced opacity or a flattened / indented contour of the humeral head was seen whereas a mineralized flap was an infrequent radiographic finding. Radiography is considered to have a high diagnostic accuracy for the detection of humeral head OC (Wall et al., 2015). In Switzerland, only neutral mediolateral views are required for official scoring. Radiographic identification of OC/OCD lesions may be improved by including additional supinated and pronated mediolateral projection (Callahan and Ackerman, 1985; Wall et al., 2015).

Subchondral bone sclerosis has been suggested a key criterion for radiographic diagnosis (Wall et al., 2015). 
However, in the present investigation, subchondral bone sclerosis alone was never diagnosed in the 2 breeds. The small number of cases with a mineralized flap may be explained by the young age of most investigated dogs. In early stages of OC, cartilaginous flaps are likely to remain uncalcified (Ytrehus et al., 2007). Magnetic resonance imaging (MRI) has been shown to be superior to radiography for the detection of shoulder OC and should be considered as an additional imaging modality in lame dogs but with normal shoulder radiographs (Wall et al., 2015). Recent studies also support the use of computed tomography (CT) as an adjunct modality for the identification and characterization of scapulohumeral subchondral bone lesions in dogs with thoracic limb lameness (Maddox et al., 2013; Lande et al., 2014).

Degenerative joint disease was significantly more common in affected joints in both breeds under investigation. This finding corrobates the diagnosis of shoulder OC, however, it should not be considered pathognomonic since radiographically OC-negative joints may show arthrotic changes, too.

\section{Conclusion}

The present study represents the first report on the prevalence of humeral head OC in a large cohort of GSMD and the BC during a long study period. Compared to other breeds, the herein reported prevalences are in the mid-upper range. True prevalences are clearly expected to be higher, as radiographs of lame and OC-positive dogs are only rarely submitted for official scoring. A likely higher prevalence should even more stimulate heritability studies and - assuming that heritability is in a range amenable to selective breeding - installation of breeding programmes. Realistic figures could be achieved if random testing was installed rather than the currently used selection mode biased towards clinically and radiographically unremarkable dogs. Random testing would not raise the total costs of screening, as not more than $20-30 \%$ of all offspring needs to be tested. Cost distribution could be achieved by installing a health fund, fed by charging breeders a modest sum for each puppy rather than charging the costs for radiographic screening to those owners only who are willing to submit their dog for radiographic examination.

\section{Prévalence de l'ostéochondrose de la tête humérale chez le Grand bouvier suisse et le Border Collie en Suisse}

L'ostéochondrose (OC) est fréquente chez les chiens de grande race. Conformément aux prescriptions d'élevage des clubs cynologiques suisses, l'articulation de l'épaule est incluse dans le dépistage radiologique des affections articulaires chez le Grand bouvier suisse (GBS) et le Border Collie (BC) et ceci depuis 1993 respectivement 2003. Le but de la présente étude était d'estimer la prévalence de l'OC de la tête humérale chez ces deux races en Suisse, sur la base des données des commissions nationales suisses de dysplasie. Toutes les radiographies ont été réévaluées pour repérer des altérations radiologiques isolées. Depuis 1993 respectivement 2003 jusqu'en 2013, la prévalence était de 14\% chez le GBC et de $8 \%$ chez le BC. Les articulations affectées montraient une opacité localement réduite ou un contour aplati/ dentelé de la partie caudale de la tête humérale. Des souris articulaires n'étaient constatées qu'occasionnellement. Les affections articulaires dégénératives étaient significativement plus fréquentes sur les articulations affectées d'OC que sur les autres (GBS: 32\%; BC: $20 \%$ ). La présente étude rapporte pour la première fois la prévalence de l'OC de la tête humérale sur une large cohorte de GBS et de BC sur une longue période. En comparaison avec d'autres races, les prévalences constatées se situent entre la moyenne et le niveau supérieur. Les résultats de cette étude doivent alerter les

\section{Prevalenza dell'osteocondrosi della testa omerale nei cani di razza Greater Swiss Mountain e Border Collie in Svizzera}

L'osteocondrosi (OC) è comune nei cani di grossa taglia. Secondo le linee guida della Società cinologica Svizzera, già dal 1993 risp. 2003, le articolazioni della spalla sono comprese nello screening radiografico per le malattie articolari nei cani di razza Greater Swiss Mountain (GSM) e Border Collie (BC). Lo scopo di questo studio, è di stimare, nelle 2 razze in Svizzera, la prevalenza complessiva di OC della testa omerale sulla base dei dati raccolti dal Comitato nazionale svizzero sulla displasia. Tutte le radiografie sono state rivalutate per stimare singoli cambiamenti radiografici. Dal 1993 e 2003, di conseguenza, e fino al 2013, la prevalenza complessiva era rispettivamente del 14\% per i cani di razza GSM e dell' $8 \%$ per quelli di razza BC. Le articolazioni colpite mostravano una ridotta opacità focale oppure un contorno appiattito/dentellato della sezione caudale della testa omerale. Occasionalmente si sono rilevati lembi articolari. La malattia degenerativa delle articolazioni era più significativamente comune in quelle affette da OC (GSM: 32\%; BC: 20\%) rispetto alle articolazioni senza OC. Il presente studio è il primo resoconto sulla prevalenza dell'OC della testa omerale di un ampio gruppo di cani di razza GSM e BC protratto su un lungo periodo. Paragonando con altre razze, la prevalenza qui riportata si situava tra la media e la media superiore.
Prevalence of humeral head osteochondrosis in the Greater Swiss Mountain dog and the Border Collie in Switzerland

S. Ohlerth et al. 
Prevalence of humeral head osteochondrosis in the Greater Swiss Moun tain dog and the Border Collie in Switzerland

S. Ohlerth et al. vétérinaires au sujet de cette affection chez ces races et peut server de pont de départ pour de futures recherches épidémiologiques et génétiques.
I risultati di questo studio dovrebbero rendere attenti i veterinari sulla malattia in queste razze e servire come punto di partenza per ulteriori studi epidemiologici e genetici.

\section{References}

Bruggeman M., Van Vynckt D., Van Ryssen B., Bolln G., Chiers K., Gielen, I., de Rooster H.: Osteochondritis dis secans of the humeral head in two small-breed dogs. Vet. Rec. 2010, 166: 139-141.

Callahan T. F., Ackerman, N.: The supinated mediolateral radiograph for detection of humeral head osteochondrosis in the dog. Vet. Radiol. Ultrasound 1985, 26: 144-148.

Coopman F., Verhoeven G., Saunders J., Duchateua L., Van Bree H.: Prevalence of hip dysplasia, elbow dysplasia and humeral head osteochondrosis in dog breeds in Belgium. Vet. Rec. 2008, 29: 654-658.

Coopman F., Broeckx B., Verelst E., Deforce D., Saunders J., Duchateau L., Verhoeven G.: Combined prevalence of inherited skeletal disorders in dog breeds in Belgium. Vet. Comp. Orthop. Traumatol. 2014, 27: 395-397.

Demko J., McLaughlin R.: Developmental orthopedic disease. Vet. Clin. North. Am. Small. Anim. Pract. 2005 35: 1111-1135.

Ekman S., Carlson C. S.: The pathophysiology of osteochondrosis. Vet. Clin. North. Am. Small. Anim. Pract. 1998 28: 17-32.

Hartmann P., Stock K. F., Distl O.: Multivariate genetic analysis of canine hip and elbow dysplasia as well as humeral osteochondrosis in the Bernese mountain dog. Berl. Munch. Tierarztl. Wochenschr. 2010, 123: 488-495.

Johnston S. A.: Osteochondritis dissecans of the humeral head. Vet. Clin. North. Am. Small. Anim. Pract. 1998, 28: $33-49$.

Kippenes H., Johnston G.: Diagnostic imaging of osteochondrosis. Vet. Clin. North. Am. Small. Anim. Pract. 1998 28: $137-160$.

LaFond E., Breur D. A. G. J., Austin D. A. C. C.: Breed susceptibility for developmental orthopedic diseases in dogs. J. Am. Anim. Hosp. Assoc. 2002, 28: 467-77.

Lande R., Reese S. L., Cuddy L. C., Berry C. R., Pozzi A. Prevalence of computed tomographic subchondral bone lesions in the scapulohumeral joint of 32 immature dogs with thoracic limb lameness. Vet. Radiol. Ultrasound 2013, 55: 23-28.

Maddox T. W., May C., Keeley B. J., McConnell J. F.: Comparison between shoulder computed tomography and clinical findings in 89 dogs presented for thoracic limb lameness. Vet. Radiol. Ultrasound 2013, 54: 358-364.

Morgan, J. P., Wind A., Davidson A. P.: Bone dysplasias in the Labrador Retreiver: a radiographic study. J. Am. Anim. Hosp. Assoc. 1999, 35: 332-340

Richardson D. C., Zentek J.: Nutrition and osteochondrosis Vet. Clin. North. Am. Small. Anim. Pract. 1998, 28: 115-135.
Wall C. R., Cook C. R., Cook J. L.: Diagnostic sensitivity of radiography, ultrasonography, and magnetic resonance imaging for detecting shoulder osteochondrosis/osteochondritis dissecans in dogs. Vet. Radiol. Ultrasound 2015, 56: 3-11.

Ytrehus B., Carlson C. S., Ekman S.: Etiology and pathogenesis of osteochondrosis. Vet. Pathol. 2007, 44: 429-448.

\section{Corresponding author}

Stefanie Ohlerth

Klinik für Bildgebende Diagnostik

Departement für Kleintiere

Winterthurerstrasse $258 \mathrm{c}$

8057 Zürich/Schweiz

Tel. 041-6358469

Fax 041-6358940

E-Mail: sohlerth@vetclinics.uzh.ch 